\title{
Elutriation: Theoretical Considerations and Methodological Improvements
}

\author{
H. Tiemann and K.-H. Betz \\ Zoologisches Institut und Zoologisches Museum der Universität Hamburg, Martin-Luther-King-Platz 3, D-2000 Hamburg 13 , \\ Federal Republic of Germany
}

\begin{abstract}
The conventional elutriation method used for separating meiofauna and sediment yields insufficiently correct quantitative results. A critical evaluation of the physical background of this method leads to the construction of a differently shaped separation funnel and to improvements allowing better controlled, gradual variations in waterflow velocity and sieve mesh sizes. Comparative tests of the conventional and the new method, using similarly composed coral sediments and organism mixtures demonstrated a significantly higher efficiency of the new method: only $5 \%$ of the organisms contained in the test samples disappeared with the new method, compared with $16 \%$ using the conventional one. Moreover, the new method elutriates with a much higher degree of purity; an average of $23 \mathrm{mg}$ sediment accumulated in the sieves, as opposed to $2380 \mathrm{mg}$ with the old method.
\end{abstract}

\section{INTRODUCTION}

Accumulation and isolation of meiobenthos organisms has increasingly attracted the attention of marine ecologists. For recent reviews consult Uhlig et al. (1973) and 'Marine Ecology', Volume III: Kinne (1976, p. $218 \mathrm{ff}$ ). Among the methods at hand, elutriation is of particular importance. Based on water-current separation, elutriation (introduced by Boisseau, 1957) involves the application of a water stream in which small organisms are washed out according to weight, volume or form; subsequently, the organisms are collected on sieves.

In the standard procedure water enters, from below, a separator funnel which contains the sample. Organisms washed out from the whirled-up sediment are forced out of the funnel via its upper part and accumulate on a sieve while the sediment remains in the funnel. Boisseau's original method has been modified by several authors according to their individual requirements. There are two main types: (1) for preserved material, an open water stream (supplied from the water mains) is used; (2) for fresh samples, a closed water system (pumpdriven circuit) with narcotized living organisms (Uhlig et al., 1973) is employed. Our own experiments with preserved samples revealed, however, that not all organisms contained in the test sample were washed out and that considerable amounts of sediment collected on the sieve when the velocity of water flow increased.
The present paper reports on a modified method characterized by improved selection efficiency. A theoretical model of flow conditions provided optimized operation conditions. These then served to construct a new, efficient elutriation apparatus. Its separation capacity was tested by means of standardized, artificially composed samples.

\section{THEORETICAL MODEL}

Organisms which are to leave the flask must have a sinking speed below the lowest flow velocity of the system. In order to determine the optimal flow velocity, it is necessary to know the sinking speed of the test particles (organisms as well as sediment particles) and to arrange for an adjustable corresponding velocity of water flow.

The sinking speed (simplified for spherical objects) is calculated as follows:

$$
\begin{aligned}
& v=\frac{2}{9} \cdot g \cdot \frac{D_{1}-D_{2} \cdot r^{2}}{\eta} \\
& v=\text { sinking speed }\left[\mathrm{cm} \mathrm{s}^{-1}\right] \\
& g=\text { gravity }\left[\mathrm{cm} \mathrm{s}^{-2}\right] \\
& D_{1}=\text { density of the particles }\left[\mathrm{g} \mathrm{cm}^{-3}\right] \\
& D_{2}=\text { density of the fluid }\left[\mathrm{g} \mathrm{cm}^{-3}\right] \\
& \eta=\text { viscosity in poise }\left[\mathrm{g} \mathrm{cm}^{-1} \mathrm{~s}^{-1}\right] \\
& r=\text { radius [cm] of spherical object }
\end{aligned}
$$




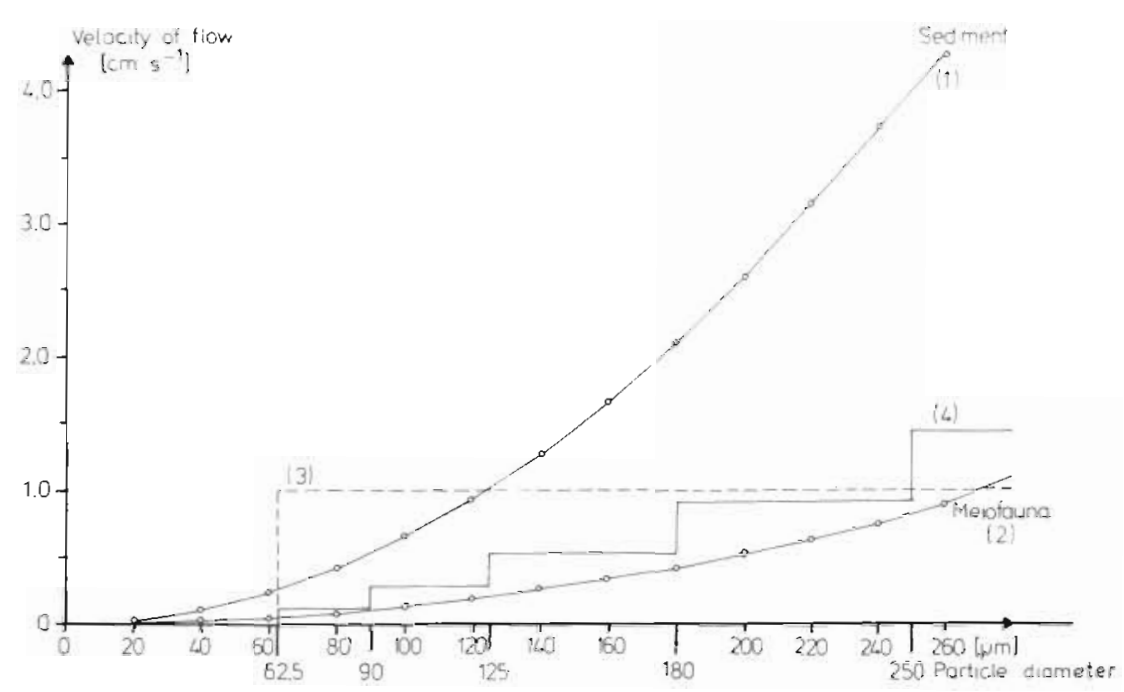

Fig. 1. Elutriation efficiency as a function of particle size and flow velocity. Compensation of sinking speed by flow velocity for sediment particles (1) and organisms (2) of different sizes. Collection efficiency of a 62.5 - $4 \mathrm{~m}$ sieve at a flow velocity of $1.0 \mathrm{~cm} \mathrm{~s}{ }^{-1}$ (3). Collection efficiency of different mesh sizes at corresponding flow velocities (4)

At constant temperature most of the variables are sufficiently steady and $v$ becomes a function of $r$.

However, in reality sediment particles, as well as organisms, diverge from the spherical shape. The degree of such divergence increases proportionally to the surface of the crosssection. Test calculations for sediment particles of square or plate shape and for more complicated forms of equal volumes showed that the section surface is less than twice that of a sphere. Compact animals are in the same range too. Organisms with elongated bodies even reach a factor of 2 or 3 .

Sinking speed is influenced not only by the resistance due to body shape but also by body density. Especially in coral sediments, which we have used for efficiency tests, the density is lower than that of compact calcite, because of its porosity. Test measurements gave $2.6 \mathrm{~g} \mathrm{~cm}^{-3}$ (standard value for calcite: $2.71 \mathrm{~g}$ $\mathrm{cm}^{-3}$ ). The density of preserved meiofauna is hardly 1.1 $\mathrm{g} \mathrm{cm}^{-3}$. More often than not the density reaches higher values, because sediment particles adhere to the organisms or are found in their guts. In consideration of these facts it is possible to calculate the theoretical differences between the sinking speeds of sediment and organisms (Fig. 1). Sediment particles located above (1) and organisms located above (2) are transported by the water flow. A constant velocity of flow, for example of $1 \mathrm{~cm} \mathrm{~s}^{-1}$ transports sediment particles up to a diameter of $123 \mu \mathrm{m}$ (intersection of [1] and [3]) and organisms up to $270 \mu \mathrm{m}$ diameter (intersection of [2] and [3]). On the left side of the diagram both particle sizes are limited by the smallest sieve used; thus in this example all particles with a diameter smaller than 62.5 $\mu \mathrm{m}$ pass through the sieve. The result is a mixture of organisms larger than $62.5 \mu \mathrm{m}$ and smaller than 270 $\mu \mathrm{m}$, and sediment grain-sizes larger than $62.5 \mu \mathrm{m}$ and smaller than $123 \mu \mathrm{m}$. Therefore insufficient separation is obtained between sediment and organisms. Moreover, larger organisms remain in the separation funnel.

Remedial measures are taken in changing the sieves according to the flow velocity fractionated elutriation). In this way it is possible to create a graduation between (1) and (2) allowing a total separation of organisms and sediment, at least theoretically (4). There are nearly no limits in fractionated elutriation concerning the size of the organisms. The degree of selectivity depends on the number of sieve steps employed. These theoretical considerations are correct only if there is a uniform flow velocity in the whole funnel without turbulence. Changes in turbulent currents can be calculated fairly exactly by means of the Reynolds number. For a maximal flow velocity of $v=$ $2.0 \mathrm{~cm} \mathrm{~s}^{-1}$ there is a maximal tube diameter of $d=7$ $\mathrm{cm}$; this is important for the construction of an elutriation funnel with optimized efficiency.

In summary, elutriation efficiency depends on the following points:

(1) The funnel must be shaped so as to (a) accommodate an adequate portion of sediment (Thiel corer, $220 \mathrm{ml}$; Thiel 1966); (b) allow the sediment to be totally intermixed by the water flow (slender cone shape and current-divider); (c) eliminate practically all turbulence; (d) reduce resistance at its upper exit so that the water flow does not hinder the organisms from leaving the funnel (gradual narrowing towards a comparatively wide exit opening).

(2) A finely graduated sieve set is required for optimizing organism collection. 
(3) The water current through the funnel must be strong enough to be correctly adjustable and measurable.

(4) A closed water circuit driven by a circulation pump is necessary to elutriate lime-stone sediments,

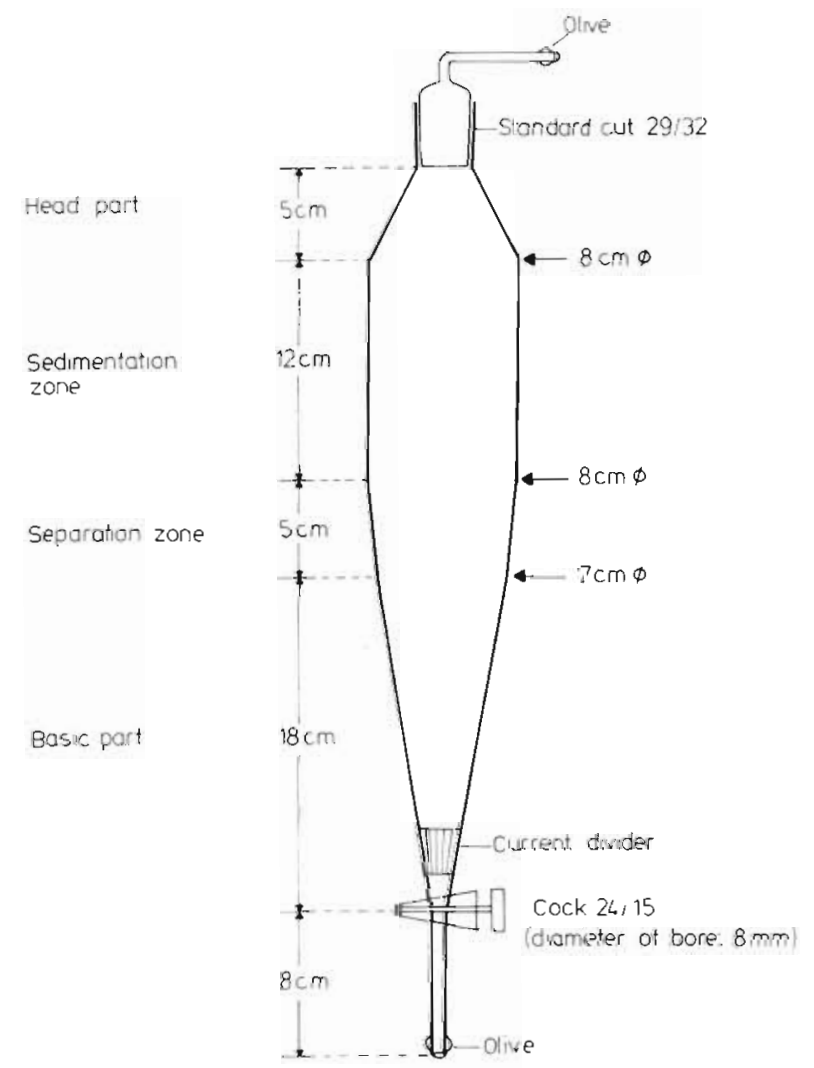

Fig. 2. Dimensions of the newly developed elutriation funnel because otherwise sediment particles are picked up by small air bubbles and transported into the sieve.

Based on these requirements we have constructed the system described below. The elutriation funnel (glass-blown) with a slender base part (200-ml volume) contains an eight-radiated current divider (stainless steel) covered with wire gauze (45- $\mu \mathrm{m}$ mesh size) (Fig. 2). A gently conical separation zone follows, which leads to a long sedimentation zone where floating particles can sediment without being affected by turbulence. In the head part flow velocity increases again, thus carrying the particles into the sieve. The water circuit is driven by a $400-W$ centrifugal pump; this requires that the reservoir be cooled.

For flow velocity measurements a hot film velocity transducer' (type 1630, Thermo-Systems Inc., St. Paul, Minnesota) was used (Fig. 3). For proper elutriation, suitable flow velocities can be obtained from Fig. 1. Elutriation with one velocity and the corresponding sieve must be continued until the organisms (Bengalrose stained) no longer leave the funnel (optical control). Thereafter the current velocity can be increased, and both sieve and mesh size be changed (fractionated elutriation).

\section{EXPERIMENTAL RESULTS}

In order to examine the efficiency of the new elutriation apparatus a number of experiments were conducted. Artificially composed lime-stone sediments and mixtures of organisms were used, with grain-sizes ranging from $62.5 \mu \mathrm{m}$ to $500 \mu \mathrm{m}$ (main fraction $180 \mu \mathrm{m}$ ). A mixture of formaldehyde-preserved copepods and

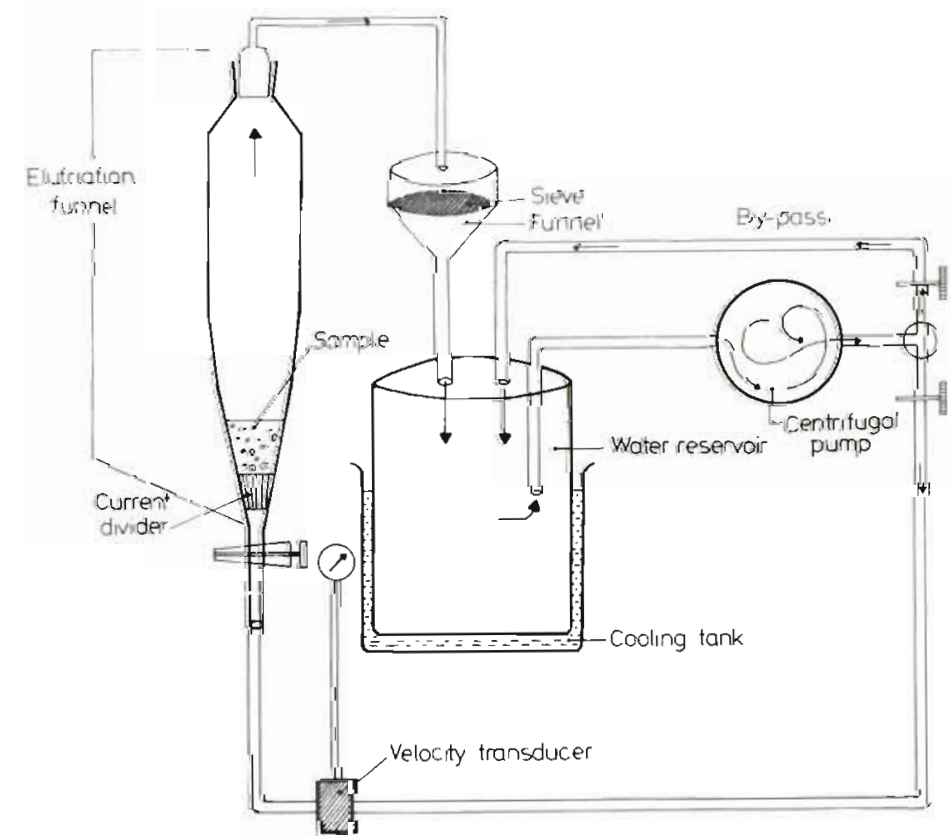

Fig. 3. Closed-circuit apparatus with the newly developed elutriation funnel 
nematodes contained Tisbe holothuriae and Anguillula silusiae at a weight ratio $2: 1$. Before elutriation the organisms were wet-weighed after standardized centrifugation. Organisms and sediment collected on the sieve by elutriating the sample were weighed again in the same way. To estimate the quantity of

Table 1. Time and sieve-changing plan of the 3 efficiency test series

\begin{tabular}{|lccc|}
\hline Method & $\begin{array}{c}\text { Sieve } \\
\text { mesh } \\
\text { size } \\
{[\mu \mathrm{m}]}\end{array}$ & $\begin{array}{c}\text { Time } \\
\text { of elu- } \\
\text { triation } \\
{[\mathrm{min}]}\end{array}$ & $\begin{array}{c}\text { Flow } \\
\text { velocity } \\
{\left[\mathrm{cm} \mathrm{s}^{-1}\right]}\end{array}$ \\
\hline $\begin{array}{l}\text { (1) Conventional } \\
\text { elutriation and }\end{array}$ & 62.5 & 15 & $\begin{array}{l}0.36 \text { (sediment } \\
\text { whirled up well) }\end{array}$ \\
$\begin{array}{l}\text { conventional } \\
\text { funnel shape }\end{array}$ & & & \\
& & & \\
(2) Fractionated & 62.5 & 20 & 0.11 \\
elutriation and & 90 & 5 & 0.28 \\
new funnel shape & 125 & 10 & 0.51 \\
& 180 & 12 & 0.91 \\
(3) Fractionated & 62.5 & 17 & 0.11 \\
elutriation and & 90 & 5 & 0.15 \\
conventional & 125 & 15 & 0.28 \\
funnel shape & 180 & 10 & 0.43 \\
\hline
\end{tabular}

organisms on the sieve, lime was dissolved in acetic acid $(10 \%, 1 \mathrm{~h})$, and the resulting weight changes of organisms and acetic-acid insoluble residues were then determined after standardization.

All tests were carried out as follows: $200 \mathrm{~g}$ of composed sediment and about $100 \mathrm{mg}$ of organisms (weighed to $10^{-5} \mathrm{~g}$ accuracy) were placed in the funnel and carefully mixed. The resulting samples were elutriated according to the time and sieve-changing plan listed in Table 1.

Test Series (1) and (2) were necessary for a proper comparison of the conventional and the presently described new modification of elutriation, Series (3) to prove how far the new shape of the funnel only is responsible for efficiency differences in comparison with the old one. The results are demonstrated in Table 2. The left column shows the percentage of organisms regained and the right the unwelcome sediment quantities being washed into the sieves. In the middle the different results are compared with each other in a matrix (Student's t-test $t_{i}$ sediment quantities in the right upper half, organism output in the lower left half).

The modified method was applied to 7 sediment samples (coral sand, Red Sea), which had been elutriated before using the conventional method. Besides the

Table 2. Conventional and modified elutriation: statistical comparison of percentage of organisms regained and sediment collected in sieves

\begin{tabular}{|c|c|c|c|c|}
\hline $\begin{array}{l}\text { Percentage of } \\
\text { organisms regained }\end{array}$ & & $\begin{array}{ll} & (2) \\
\text { Sediment: } & 23.3 \mathrm{mg} \\
\pm & 13 \mathrm{mg}\end{array}$ & $\begin{aligned} & (3) \\
\text { Sediment: } & 66 \mathrm{mg} \\
\pm & 33 \mathrm{mg}\end{aligned}$ & Sediment quantity \\
\hline $\begin{array}{l}\text { (1) Conventional } \\
\text { elutriation } \\
\text { and conventional } \\
\text { funnel shape } \\
\qquad 84 \% \pm 7 \%\end{array}$ & & $\begin{array}{l}\text { Difference signifi- } \\
\text { cant with a proba- } \\
\text { bility of } 99.9 \% \\
t=5.71 \\
9 \text { degrees of freedom }\end{array}$ & $\begin{array}{l}\text { Difference signifi- } \\
\text { cant with a proba- } \\
\text { bility of } 99.9 \% \\
t=5.08 \\
9 \text { degrees of freedom }\end{array}$ & $\begin{array}{l}\text { (1) Conventional } \\
\text { elutriation } \\
\text { and conventional } \\
\text { funnel shape } \\
\text { Sediment: } 2380 \mathrm{mg} \pm \\
1260 \mathrm{mg}\end{array}$ \\
\hline $\begin{array}{l}\text { (2) Fractionated } \\
\text { elutriation and } \\
\text { new funnel shape } \\
\qquad 95 \% \pm 5 \%\end{array}$ & $\begin{array}{l}\text { Difference signifi- } \\
\text { cant with a proba- } \\
\text { bility of } 98 \% \\
t=3.04 \\
10 \text { degrees of freedom }\end{array}$ & & $\begin{array}{l}\text { Difference signifi- } \\
\text { cant with a proba- } \\
\text { bility of } 99 \% \\
t=3.35 \\
12 \text { degrees of freedom }\end{array}$ & $\begin{array}{l}\text { (2) Fractionated } \\
\text { elutriation and } \\
\text { new funnel shape } \\
\text { Sediment: } 23.3 \mathrm{mg} \pm \\
13 \mathrm{mg}\end{array}$ \\
\hline $\begin{array}{l}\text { (3) Fractionated } \\
\text { elutriation and } \\
\text { conventional } \\
\text { funnel shape } \\
\qquad 83 \% \pm 6 \%\end{array}$ & $\begin{array}{l}\text { Difference not } \\
\text { significant } \\
t=0.22 \\
11 \text { degrees of freedom }\end{array}$ & $\begin{array}{l}\text { Difference signifi- } \\
\text { cant with a proba- } \\
\text { bility of } 99.9 \% \\
t=4.34 \\
13 \text { degrees of freedom }\end{array}$ & & $\begin{array}{l}\text { (3) Fractionated } \\
\text { elutriation and } \\
\text { conventional funnel } \\
\text { shape } \\
\text { Sediment: } 66 \mathrm{mg} \pm \\
\quad 33 \mathrm{mg}\end{array}$ \\
\hline & (1) $84 \% \pm 7 \%$ & (2) $95 \% \pm 5 \%$ & & \\
\hline
\end{tabular}


organisms a great quantity of sediment had been collected on the sieve (organisms plus sediment: on an average $24.2 \mathrm{~g} \cdot$ sample $\left.^{-1}\right)$. The samples contained a wide range of species including polychaetes of considerable size, which made the application of mesh sizes up to $355 \mu \mathrm{m}$ necessary. After fractionated elutriation with the new elutriator, $22.9 \mathrm{~g}$ of sediment could be separated from the $24.2 \mathrm{~g}$ sample $(90.4 \% \pm 7.4$ weight$\%$ ), which is an increase in meiofauna purity of a factor of 10 .

\section{DISCUSSION}

The new elutriation method described is clearly superior to the conventional one. This superiority has been achieved by two modifications of the old method: (1) simultaneous changing of sieve mesh size and flow velocity; (2) a newly designed separation funnel.

For discussing the quality of an elutriation method two aspects are important: the quantity of organisms retained (in relation to the original quantity contained in the sample) and the purity of the elutriated organisms which is a function of the quantity of sediment collected on the sieve.

Changing sieves and flow velocity (1) mainly increases the degree of purity as proved by employing fractionated elutriation with the conventional funnel: the quantity of sediment could be reduced from $2380 \mathrm{mg}$ to $66 \mathrm{mg}$. Smaller quantities of sediment are found on the sieves because small particles leaving the funnel in the respective flow velocity pass the specific mesh size, while greater sized ones with higher sinking speed remain in the funnel.

The new shape of the elutriation funnel (2) largely meets the theoretical demand; $95 \%$ of the organisms are retained due to uniform sediment intermixture (steep funnel shape, current-divider) and the practical absence of turbulence. The output of only $84 \%$ in the old design is due to the enormous turbulence or insufficient intermixture of the sediment. Not only the quantity of organisms retained but also the purity could be raised by introducing the new funnel shape (from 66 $\mathrm{mg}$ to $23.3 \mathrm{mg}$ ). Thus, only a third of the organisms is lost and a third of the sediment washed into the sieves as compared with the conventional funnel.

The advantages described above are achievable only at the price of higher investments in terms of equipment and time: a special-made elutriation funnel, a velocity transducer and a sieve set; instead of 15 min one elutriation takes about $45 \mathrm{~min}$. This higher investment is well compensated by facilitating the sorting (by hand) of the sieve-contents, which as a rule contain more organisms than sediment. The benefits obtained are likely to be applicable to quartz sediments since lime and quartz have nearly the same densities. Preliminary tests show that quartz particles and organisms can be easily separated. Only small quantities - especially mica particles - were washed into the sieve.

\section{LITERATURE CITED}

Boisseau, M. J.-P. (1957). Technique pour l'étude quantitative de la faune interstitielle des sables. C. r. Congr. Socs sav. Paris, Sect. Sci., 1957, 117-119.

Kinne, $\mathrm{O} .(1976)$. Cultivation of marine organisms: waterquality management and technology. In $O$. Kinne (Ed.), Marine Ecology, Vol. III, Cultivation, Part 1. Wiley, London. pp. 19-300.

Thiel, H. (1966). Quantitative Untersuchungen über die Meiofauna des Tiefseebodens. Veröff. Inst. Meeresforsch. Bremerhaven, Sbd., 2, 131-147.

Uhlig, G., Thiel, H. and Gray, J. S. (1973). The quantitative separation of meiofauna. Helgoländer wiss. Meeresunters., 25, 173-195

This paper was presented by Dr. D. Siebers; it was accepted for printing on September 4, 1979. 